Janny HC Leung*

\title{
Negotiating language status in multilingual jurisdictions: Rhetoric and reality
}

DOI 10.1515/sem-2016-0013

Abstract: About a quarter of legal jurisdictions in the world operate in more than one language. Despite this, language policies governing the functioning of law in such jurisdictions, other than in the European Union, rarely receive much attention in research. Given, however, that the policy contrast between legal monolingualism and multilingualism is often a matter of strategic response to the rising or declining power of one or more particular language communities, the conferring of legal authority on some language(s) but not others calls for analysis. Advocacy and justification surrounding potential or actual change of legal language, for example, consists of competing rhetorics advanced by politicians, legal professionals, and campaign groups, and to this extent politics permeates both the promotion and presentation of legal multilingualism, despite reluctance among legal policy makers to engage directly with this aspect of the process. This article situates legal multilingualism within a wider understanding of multilingualism and language policy. It first surveys status labels assigned to languages in multilingual jurisdictions. It then compares, across jurisdictions, rhetorical strategies deployed in promoting and opposing specific proposals about language status, in both official and public discourses, and analyses contradictions and dilemmas embedded in them. The argument extends [Rhetoric as jurisprudence: An introduction to the politics of legal language. Oxford Journal of Legal Studies 4(1). 88-122] observation that legal discourse is pre-eminently a discourse of power. But if use of legal language is political, it is suggested, then the processes of negotiation which establish a language for such use are even more so.

Keywords: legal bilingualism, multilingualism, rhetoric, legal language, language status, official language, language policy

\section{Introduction}

Nationalist ideologies and centralized power in nation states use the idea of a national language to foster a sense of shared identity. A decision as to which

*Corresponding author: Janny HC Leung, University of Hong Kong, Hong Kong, E-mail: janny@cantab.net 
language or languages should be chosen to represent a nation, as its national language(s), is inevitably political. Any such language policy decision, at whatever level of explicit policy formation it is made, creates a status hierarchy, reshapes identity, and affects relationships between linguistic communities. When it comes to deciding on the language to be used in law in particular, the situation is still more complicated. This is partly because legal systems are saturated in language; indeed, they are largely constructed primarily out of language. It is also partly because linguistic decisions have a major effect on the scale of resources available to groups who are all subject to the same law but live within different language communities, as a result, such decisions have an important effect on equality of access to justice. Of crucial importance in relation to the proper conduct of law, for instance, is the principle of the certainty of meaning of statements of law; but this principle is potentially undermined by differing perceptions of meaning across authorized legal languages and their users $^{1}$ (Leung 2013).

Such problems are commonly acknowledged. In any given national situation, there will normally be fewer official languages than the number of languages spoken by people living within that nation. Amidst competition for legitimacy, how do linguistic communities (and those who lead them) argue that their language should be accorded a higher status than others? When such linguistic decisions are made in respect of law, as the central instrument of political authority, problems of argumentation and justification are compounded. What ideologies and values related to language and law, and to the combination of the two, are revealed by forms of advocacy produced in such circumstances? And how credible are arguments put forward that one language is inherently better as a legal language than another? Tensions about language status are central to political contention but rarely visible in legal instruments themselves, as is well captured by Goodrich's words below:

In reading the law, it is constantly necessary to remember the compositional, stylistic and semantic mechanisms which allow legal discourse to deny its historical and social genesis. It is necessary to examine the silences, absences and empirical potential of the legal text, and to dwell upon the means by which it appropriates the meaning of other discourses and of social relations themselves, while specifically denying that it is doing so. (Goodrich 1987: 204)

1 How legal multilingualism affects statutory interpretation in jurisdictions that uphold the equal authenticity principle was explored in an earlier article. 
In a similar spirit, this paper seeks to gauge such tensions in wider legal and public discourse in multilingual ${ }^{2}$ jurisdictions. Language status politics is also found in monolingual jurisdictions, but having an established de jure or de facto national or official language often leaves limited room for it. By contrast, multilingual jurisdictions often celebrate multiculturalism and experience vigorous and explicit negotiation of language status, and thus provide a particularly valuable window through which to examine the research questions set out above.

According to the Office of the Commissioner of Official Languages in Canada, there are forty-five bilingual or multilingual state ${ }^{3}$ in the world (for an updated figure and a comprehensive overview, please see Leung forthcoming). Labels assigning the status of specific languages in such multilingual states are surveyed in the first part of the article. Such discourse conventions governing multilingual practice in law in particular typically develop within this larger field of multilingual social policy, and reflect important but varying conceptualizations and ideals of what legal multilingualism should be. The second part of the article explores such conceptualizations, contrasting how legal multilingualism is spoken and written about at two different levels: first, in official and public domains within one jurisdiction; and second across jurisdictions (including but not limited to Hong Kong, Malaysia, the Philippines, and Switzerland). Discourse at these levels negotiates and interprets policies differently. The analysis compares official rhetoric used to promote the status of a language, with rhetorical strategies employed in opposition to them. In this way, the article extends the existing literature concerned with legal rhetoric, which typically focuses on rhetorical arguments presented during a trial (for example see Burns 2003). At the same time, it focuses wider discussion of language policy on one exemplary, specialized site of required implementation, from social-cultural and cross-jurisdictions perspectives. It is argued that assignment of language status in multilingual societies has become a battlefield of class and racial politics, sometimes thinly disguised in linguistic and legal terminology. The article concludes by assessing some of the implications of this claim.

2 For the sake of simplicity, I use the term multilingualism throughout to signal use of two or more languages in a legal system, hence as a catch-all term for both legal bilingualism and multilingualism.

3 This figure does not include the bilingual jurisdictions of Hong Kong and Macau, which are not sovereign states. 
There are inevitably limitations in the scope of a single article faced with this large and largely unexplored field. ${ }^{4}$ My analysis is not concerned, for example, to assess the relative merits of particular language policies which are discussed. Instead, it explores the rhetorical frameworks of explanation and advocacy that underpin them. Neither is it possible within the scope of this article to describe in full the socio-political and cultural history of each jurisdiction (though I contextualize highlighted discourses where necessary); and my survey of multilingual jurisdictions is not intended to be exhaustive. Further, while supranational bodies such as the European Union (EU) are clearly multilingual jurisdictions, I devote more attention to legal multilingualism at the national level (for a recent discussion of the politics of EU's multilingual policy, see Romaine 2013). I also confine discussion to jurisdictions where legal materials (official documents that describe bilingual/multilingual policies) and relevant public discourse (mostly from mass media) are available in English. These data come from different periods as jurisdictions adopted their language policies at different times. Finally, it should be noted that, because of the vibrant dynamics associated with their current multilingual development, I have drawn particularly on documentary sources related to a number of postcolonial jurisdictions in Asia.

\section{Status labels in multilingual jurisdictions}

Labels that assign language status also project value systems. This general claim not only reflects the constitutional fact that such labels are embedded in more encompassing legislative frameworks but also matches the day-to-day experience that official recognition of a language enhances its perceived worth, extends its use in different settings, improves its vitality, and attracts people to learn it.

Among the labels used to describe languages in a multilingual legal context are to be found a number of common adjectives, including "official," "national," "working," "authentic," "link," and "heritage." Each of these adjectives prescribes a basis for coexistence among two or more languages. Yet these

\footnotetext{
4 There is some literature that has taken a socio-political perspective to language policy, but few do so in the legal context, and those who do tend to focus on one policy in one jurisdiction (e. g., Abdelhay et al. 2011; Warhol 2012). Krzyżanowski and Wodak (2011) studied how language policies have become tools for political macro-strategies in the European Union; in this study only official documents were analysed.
} 
terms cannot be arranged in any straightforward value series or hierarchy. Further clarification is therefore needed in order to set the stage for discussion of how language status is assigned, and how such status is negotiated and contested between affected parties. Notwithstanding the fluidity of the labels, including the possibility that some countries apply them in a more idiosyncratic manner than others, I attempt below to generalize across different national experiences in my characterization of the main import of each.

\subsection{Official language}

According to the Official Languages and Bilingualism Institute (OLBI) in Canada, "(w)ithout a doubt, the most prestigious status for any language is that of official language, because states or countries that grant it automatically commit to using that language in all of their operations."

An "official" language, in this sense, is a language used in administration. The term essentially denotes authority. Official languages may enjoy equal status, as in the case of English and French in Canada. It is also possible for some official languages to be given higher status than others, depending on the scope of usage or prescribed priorities. For instance, Romansh, which is spoken by $0.5 \%$ of the Swiss population (according to the 2000 census), is an official language in Switzerland, but unlike the other official languages German, ${ }^{5}$ French, and Italian is only used for dealing with Romansh speakers and therefore is sometimes described as only semi- or partially official (Schmitt 2005). By contrast, in Ireland the Irish language, though only spoken by $1.1 \%$ of the population as a first language ${ }^{6}$ (according to the OLBI website), is designated as the first official language as a proactive policy to promote it; English, despite usage figures, only comes second. Although South Africa has eleven official languages, English and Afrikaans are the most dominant languages (Mesthrie 2002).

"Official" can function slightly differently in postcolonial territories. In these settings, ex-colonizers' languages sometimes remain as an official language because of their practical value, for example in a judicial system that is already deep-seated in the language. A choice of this kind potentially creates a kind of linguistic recolonization (or linguistic imperialism, Phillipson 1992), as arguably

5 Swiss German is used as the spoken form, and High German as the written language.

6 Note that Romansh and Irish native speakers are nearly all bilingual in another official language. 
in the case of jurisdictions such as Hong Kong and the Philippines. A still more complicated kind of linguistic recolonization took place in East Timor. There, instead of retaining Bahasa Indonesia, the language of the immediate ex-colonizer, the government reinstated Portuguese, the language of the preceding colonizer, as its official language along with the mostly widely spoken local language Tetum (Macalister 2012).

\subsection{National language}

The term "national," as applied to a language, symbolizes national identity. A national language is usually indigenous, has some vitality (i. e., that it is in active use; see UNESCO 2003 for assessment methods), and has political significance in the formation of the nation. The one-nation one-language ideology has dominated western nations for centuries (Hornberger 2001), and thus 'national language' often appears in the singular. In nineteenth century Europe, language was considered "the major defining factor of a nation" (Safran 2004). "National" languages often also function as official languages, though this is not always the case. Back to the Swiss example - Romansch is only semi-official despite the fact that it was adopted as the fourth national language in 1938 (which some saw as "an impractical exercise in symbolism" McRae 1983: 120). While a national language may not be the language most frequently used by the administration and the public, its intimate connection with the culture and history of a nation may nevertheless render it symbolically important. Ex-colonizing languages for this reason tend not to become a national language in postcolonial territories, although resources from the ex-colonizer's language may be borrowed (e. g., as loan words; Fishman 1972).

Consider Ireland as an example again. According to Article 8 of the Irish Constitution, the Irish language is the national language and serves as a marker of the Irish cultural heritage. Although English is spoken by the vast majority of the population, it remains an official but not a national language. Similarly in Singapore, Malay is the national language, due to historical ties, despite the fact that English, as one of the four official languages, ${ }^{7}$ is the lingua franca of the various ethnic communities living in Singapore ${ }^{8}$ and is also the dominant language used in administration and education.

7 As stated in 153A Official languages and national language, the Constitution of the Republic of Singapore.

8 Mandarin is also growing in importance in the nation. 


\subsection{Working language}

A “working” language is a procedural/instrumental language used by multilingual parties where it is impractical to adopt the languages of all the parties involved as a channel of communication. Although choice of working languages inevitably subverts any principle of language equality, use of the term seeks to remain above the kinds of ideological conflict and power struggle that can surround language selection by appealing explicitly to pragmatic concerns.

Singapore provides such an example. Although Malay is the national language of Singapore, and four languages are listed as official languages, English has been recognized as the country's working language. In legal proceedings, for example, all hearings in the Supreme Court are conducted in English. According to the country's former Prime Minister Lee Kuan Yew (Lee 2011), although $75 \%$ of the population was Chinese when Singapore became independent in 1965, choosing Chinese as the working language might have encouraged the $25 \%$ non-Chinese to revolt. English accordingly presented itself as the optimal choice, given the political, economic and geographical realities of the country at the time.

At supranational level, although the number of official languages of the EU has proliferated to reflect its expanding membership, only three of these official languages - English, French and German - are informally known as the working languages 9 (paradoxically rendering the remaining languages on the list "merely" official languages). The working languages are the languages through which the EU operates internally. By contrast, languages included in the larger number of "official" languages are used for external communication, according to the European Commission Directorate-General for Translation (European Commission Directorate-General for Translation 2010). There has also been discussion about whether English should be adopted as its single working language (Ammon 2006). Such discussion reflects a tendency, moving up a geographical level beyond national and supranational levels, for English to be described informally as now the "working language" of the global village (Svartvik and Leech 2006).

\subsection{Authentic language}

"Authentic" languages relate more specifically to legal systems. They are languages in which the judiciary of a country can formally and legitimately

9 Officially all official languages of the EU are also its working languages, but in practice English and French are used most often and German occasionally. See Ammon 2006. 
function, based on relevant constitutional procedures. The "authentic language" versions of a source of law have legal force, while versions written in nonauthentic languages are for informative purposes only. Authentic texts of the law are those presumed to represent the intention of the legislature.

In some legal jurisdictions, such as Canada and Hong Kong, the official languages are held to be "equally authentic." This designation has the consequence that one authentic language text should carry the same legal meaning and force as another. In practice, however, legislative history and drafting procedures can affect the application of such notionally equal legal sources. For instance, the fact that in Hong Kong the Chinese texts of many ordinances are translated from English originals has allowed judges to give more weight to the English texts of the law (Leung 2012). In the EU this practice is specifically forbidden; judges are obliged to work to reconcile different authentic versions (Shelton 1997).

\subsection{Other labels}

English is often described as a "link language" in India and Sri Lanka, where it serves to connect its linguistically diverse populations and to bridge its legal system with the common law world, but its identity as the former colonizer's language deems it unsuitable to be designated other labels with more symbolic significance.

A heritage language, like a national language, has symbolic and cultural significance, but the label comes with little political power; it is typically associated with languages spoken by a minority community. This label is frequently used to denote aboriginal or native languages, for example in Australia and Canada. The same label is also used, sometimes interchangeably with "community language" or "international language," to describe the first language of migrants to Canada and the United States, whose offspring grow up speaking English and may or may not speak the ancestral language.

\section{Rhetorical strategies for elevating the status of a language}

The terms glossed above provide core categories around which arguments as to language selection in multilingual societies are developed. Given that use of such terms in a country's language policy results in status hierarchies, the next 
question to be addressed is therefore: on what basis do countries justify rewarding one language with greater symbolic worth than another?

Quite evidently linguistic demographics and patterns of current use will be an important consideration. But facts about use alone do not explain language practices particularly well. They do not even dominate in the relevant discourses of advocacy and justification. Rather, how a country projects its language policy paints an image of the society in question - an image that reflects ideology and social values as well as user numbers. In this section, accordingly, I examine statements regarding the status of specific languages in multilingual countries made by relevant national authorities, before moving on (in the next section) to look more specifically at legal systems. The statements considered in the current section are drawn from policy documents, statutes, and speeches made by public officials. Rather than illustrating alternative positions in detail, however, I focus on those aspects of such statements which convey contrasting policy rationales and which foreground the range of rhetorical techniques used in articulating such rationales.

Some of the common rhetorical tropes involved in official presentations of language policies revolve around individual rights, equality, diversity, value, national identity and cultural heritage, and often bring together legal, political, and wider cultural considerations.

The bijural jurisdiction of Canada provides an example of how such concepts can underpin policy. Canadian bilingual policy is founded on a principle of individual rights, and linguistic duality (involving English and French) is seen as an essential component of the country's national identity and cultural heritage. Promoting the two official languages is part of the mission of the Department of Canadian Heritage, ${ }^{10}$ linking specifically legal choice with other aspects of wider cultural policy. In a document published by Office of the Commissioner of Official Languages that provides an overview of the Official Languages Act (Office of the Commissioner of Official Languages 2010), reflecting this wider cultural strategy, the official languages are described as being "at the heart of our identity." Particular emphasis is given to the notion of 'equality' in the Act, which aims to "ensure equality of status and equal rights and privileges" regarding the use of the official languages (Section 2). Part IV of the Act does not require every Canadian to speak both official languages; rather, it gives English- and French-speaking citizens the right to communicate with any federal office in the language of their choice. Part VII of the Act ensures that

10 http://www.pch.gc.ca (accessed 18 December 2015). 
official language minority communities ${ }^{11}$ enjoy the same rights as the rest of the population. These language rights are underpinned by the Canadian Charter of Rights and Freedoms, which is embedded in the Constitution Act 1982. Such provisions portray a society in which two communities maintain their respective linguistic heritage and live harmoniously alongside one another. Emphasis placed on individual rights means that the burden falls on government, rather than on citizens themselves, to be fully bilingual in order to allow citizens to function monolingually.

The equivalent discourse in Switzerland also conveys a vision of national identity and linguistic diversity, but without any emphasis on the notion of equality. The country is conceptualized as a Willensnation: a country united by the desire of its citizens to live together with their diversities (Schmitt n. d.). Switzerland is "defined precisely by its linguistic diversity, gaining its sense of national self and expressing its very soul through diversity, not in spite of it," according to Francois Grin, Deputy Director of European Centre for Minority Issues (Grin 1998: 2). But in contrast with Canada, attempts to introduce a notion of equality into the country's language policy have been thwarted. A draft bill, the Federal Language Act, which contained the principle that the four national languages should be treated "identically" (Section $3^{12}$ ), was abandoned in 2004 because such a policy would be too expensive (Lucini 2004). Instead, the Federal Act on National Languages and Understanding between the Linguistic Communities eventually came into force in 2010. That Act seeks to promote multilingualism and protect minority languages, but in this revised version of the bill the stated commitment to equality is limited to only three of its four national languages, with Romansh omitted. Similarly, discourses about diversity and emancipation have replaced assimilationist approaches in both South Africa and Bolivia, following multilingual policies implemented in the 1990s (Hornberger 2001), but equal status is only granted to official languages.

Another common rhetorical strategy in arguing for a particular language policy is to emphasize the practical value of the language chosen. In the countries discussed in this section so far, languages were selected as "official" because they were spoken by the dominant linguistic communities when the nation was built. By contrast, when Singapore became independent - a different and more recent model of nation-building - the dominant ethnic groups were

11 Referring to "English-speaking communities in Quebec and French-speaking communities in a territory or in a province other than Quebec," see website of Office of Commissioner of Official Languages at http://www.ocol-clo.gc.ca/html/act_loi_e.php (accessed 18 December 2015).

12 Complete text of the draft bill available at https://www.slmc.uottawa.ca/?q = bi_switzerland_ national (accessed 18 December 2015). 
Chinese, Malay and Indian. Yet as has been indicated above, English, the excolonizing language, was given special status in addition to being an official language along with Malay, Mandarin Chinese, and Tamil (Lim et al. 2010). English was chosen as the working language of the country in order to strengthen connections between Singapore and the external world and to diffuse Malay nationalism, especially given the neutrality of English as a language in relation to racial conflicts that immediately preceded the country's independence (Rappa and Wee 2006). The idea that a foreign language is capable of uniting a country may seem improbable, but the policy is pragmatically motivated and has become part of the core of Singaporean national identity. Former Prime Minister Lee Kuan Yew declared that, "We decided to opt for English as a common language and it was the only decision which could have held Singapore together. If we had Chinese as a common language, national language, we would have split this country wide apart, and we would be foolish to have Malay or Tamil” (T. P. 2011).

From this remark it is possible to infer that, although Chinese, Malay, and Tamil are the country's official languages - with Malay doubling as the national language as well - these statuses have predominately only symbolic value. Unlike the Canadian model, which emphasizes individual rights and places linguistic obligations on the state, in Singapore the burden is on its citizens to adapt to the social engineering imposed by the state, such as campaigns that aimed at conformity to language policies (Lim et al. 2010).

Somewhat similarly, adopting Chinese as an official language provided an obvious means of recognizing change of sovereignty when Hong Kong was returned to China in 1997. On one view, such a decision would have been a matter of dignity and politics (Justice Findlay 1999). Nevertheless, English has been retained as an official language for its practical value, both commercially and also legally because of the bridge the English language offers to other common law jurisdictions. Few have claimed - as might be expected in rhetorics concerned with rights, citizenship, and nationalism - that adoption of two official languages helps to improve the unity or diversity of the people of Hong Kong. Rather, discussion has tended to focus on how the two languages together can help Hong Kong to develop a competitive edge as an international financial center, given its location (see an analysis of how English fulfills instrumental needs in Morrison and Lui 2000).

The kinds of legal and political discourse promulgated in relation to multilingual policies, then, tend to rely on a combination of elements. The exact combination of elements varies according to the relative degree of appeal associated in a given situation with concepts including individual rights, equality, cultural heritage, diversity, national unity, and practical usefulness. These 
are all notions available to be deployed in different cultural and political circumstances. What they have in common is their immediate linkage to popular values such that, once a policy is proposed as being based on some mix of these values, it will hardly require further justification. Potentially obscured in forms of argument based on variable combinations of such values, however, is the possibility that the resulting language policy may nevertheless not be the best way of realizing the particular ideal or ideals canvassed, not least because the values involved are not absolute, have no truth value, and may sometimes conflict with one another.

This is easy to illustrate where countries are selective in framing their statements of language policy. When strategies are promulgated based on the notion of individual rights, for example, or on cultural heritage and diversity, the (conceptually equivalent) rights of those minority language speakers whose language will not be accorded elevated status (including indigenous people or immigrants) are rarely mentioned. Or when, alternatively, the practical value of an official language is what is emphasized, attention is inevitably deflected away from its representativeness. It seems that each rhetoric is obliged to swing between two ideals that cannot co-exist. Or, as political theorist Kukathus (2002:185) puts it, diversity and equality are simply incompatible concepts, and "attempts to promote one can only be made at the expense of the other."

Such selectiveness can be shown more fully in other cases. Despite diversity being a central, stated value central of Swiss identity, Romansh speakers of other idioms ${ }^{13}$ than standardized Rumantsch Grischun (RG), as well as other minority groups such as the Yenish, often feel left out: against the backdrop of celebrating the linguistic diversity of the country and promoting RG as an official language, many regional idioms are being phased out (Ball 2011). What counts as cultural heritage is also subject to interpretation. In Canada, indigenous groups have a longer history on the land than English and French colonizers (which began in late fifteenth century; Riendeau 2007), but they are seldom included in the picture painted by official language discourse (see Fettes 1998 for discussion on how official bilingualism hinders the development of Aboriginal languages in Canada).

Rhetorical tropes of national unity and language diversity can also sometimes compete with each other, as countries shift their footing between the two concepts in order either to narrow or broaden the scope of use of particular

13 More commonly known as "varieties" in the sociolinguistic field; the term "idiom" enjoys wide usage in the Swiss language context. 
languages. In Singapore, for instance, when English was designated a working language and placed above other official languages on the strength of its unifying capability and practical value, cultural heritage and diversity had to be downplayed. The latter values were realized only symbolically, by other languages being assigned national and official status. How Singapore manages its bilingual policy is also striking (Rappa and Wee 2006). Mother tongue is officially assigned; children of mixed marriages are assigned the father's ethnicity. English has to remain an ethnically neutral language and cannot be considered mother tongue (while in reality it has become the mother tongue of younger Singaporeans). Singaporeans are expected to speak both their assigned mother tongue and English. As Safran (2004) reminds us, language policy is as much about nation-building as political control.

Also notable in the complex balancing of different arguments in formulating overall language policies is powerful external pressure exerted by the rise of English as a global language. Such pressure was reflected, for instance, in economic value prevailing over other considerations when Singapore adopted English as its working language. Even in countries which are not former British colonies, there have been heated discussions about introducing English as an official or semi-official language on account of its practical, in this case potential economic value. A Swiss national research programme, for instance, has suggested that Switzerland adopt English as a semi-official language in order to "bring Switzerland an advantage in international fields where English is the dominant language" (Dacey 2009). Proposals to make English an official language have also been debated in monolingual countries such as Japan (Hashimoto 2002), Thailand (Ahuja 2011), and South Korea (Song 2011). Quite strikingly, the new nation of South Sudan has chosen English as its official language because it will make the country "different and modern," according to the country's Minister of Higher Education Edward Mokole (Goldsmith 2011), despite there being very few fluent English speakers in the country. For similar reasons English was also introduced as the third official language of Rwanda in 2008, sharing equal value with French and Kinyarwanda (Gateraruke 2012).

\section{Rhetorical strategies for undermining the status of a language}

In the official depictions of multilingual policy described above, it is nevertheless common to find tensions behind an inclusive and amiable façade created by the tone and approach adopted in particular documents. In this section 
I examine forms of discourse about multilingual policy which seek to re-negotiate language status, or undermine the status already accorded to a particular language, often by countering the ideology or cultural values embedded in the justification offered for an earlier or proposed official choice. Such counterdiscourses are not monologues which exist independently of official discourses they oppose. Public voices which seek to re-negotiate language status form a shifting background against which official language policies are promulgated and implemented, and are in ongoing dialogue with them.

Opposing discourses flourish especially in postcolonial jurisdictions, where citizens are likely to feel a stronger sense of participation in nation-building than previously and may therefore be more given to imagining how their emergent nation can continue to grow beyond the present realities of state. In many circumstances, such discourse is facilitated by the vulnerability of any belief that multilingualism is a finished, static product, even in countries where relevant language policies have been incorporated into law. Language ecology is not exclusively, or possibly even primarily, driven top-down, and even language ideologies that have been fully institutionalized, including by means of legislation, may not reflect public sentiment or aspiration.

As such, language policy discourses considered in this section show a kind of resistance to publicly stated policy, as well as sometimes specific challenges to selection of particular official and non-official languages. Public voices informally presented here to illustrate such viewpoints are taken as samples from newspaper interviews and columns, academic texts, and online commentaries where the writer is identified. Searches were performed on the web, news and academic databases using names of minority languages, and relevant discourses identified. My treatment of these kinds of counter-discourse is organized - as above, with the account of official statements of policy - less as detailed commentary than as a rudimentary typology of rhetorical strategies employed. Each of the discourse strategies I consider surfaces not only in relation to a country's multilingualism in general, but in relation to challenges presented by the selection of particular languages for use in the country's legal system.

On the basis of the directly stated propositions in the sources examined, I suggest it is possible to identify five main oppositional strategies.

\subsection{Challenging the representativeness of the language}

One obvious and prevalent strategy in contesting an official representation of multilingual policy is to challenge the representativeness of the language given special status. This line of contestation may be developed in multilingual 
societies where one, or more than one, language has been chosen as an official language but others have not, or in legal jurisdictions which attempt to create a localized Esperanto if there are too many local dialects to be practically adopted for legal purposes. In such cases, interlocutors in any public dispute about language policy will disagree over, for instance, whether the chosen official language or languages can unify the nation, whether they sufficiently represent the country's diversity or satisfy people's individual rights. Challenges to official policy are also likely to involve complaint about the artificiality of planned intervention in language use.

In the Philippines, for example, both Filipino and English are official languages but only the former is the national language. Filipino is a language constructed on the basis of Tagalog, a local language spoken in and around Manila, with borrowings added from English and Spanish but "unfortunately" not much from other native Philippine languages (Rubrico 2001). While many people call for a strengthening of the use of Filipino (including in the legal system, where English is still used as the dominant language), there are also Cebuano critics who have described Filipino as a disguised form of Tagalog and its adoption as the national language as renewed "imperialism" imposed on a country that speaks more than a hundred languages (Maceda 2003: 105). When an Executive Order mandated, in 1989, that all official communications should be conducted in Filipino, 97 Congressmen objected, arguing that Filipino as a language “does not exist” (Maceda 2003: 105).

In a similar vein, in Switzerland RG has been criticized in terms of its history, origin, and representativeness. RG was created in 1982 in order to provide speakers of five different Romansh idioms with a standard written language; its adoption is sometimes viewed as a cost-cutting measure adopted to avoid the same material having to be printed in all five idioms. The artificiality of the resulting idiom has been widely criticized, however. "Romansh is something which has grown and become established, you cannot replace that with another language that has been artificially constructed," says Annemieke Buob, president of an organization which promotes Romansh (Leybold-Johnson 2006a, 2006b). A local language teacher, Renata Bott, complained to a Wall Street Journal reporter that it is "ridiculous to make kids learn a language they don't understand and that no one speaks"; and the leader of a Pro-Idioms group Domenic Toutsch has called RG simply a "bastard language" (Ball 2011), pinpointing the perceived illegitimacy of the language in his use of a kinship relation term extending the semantic field triggered by "mother tongue." Fuelled by emotional attachment to a speaker's "mother tongue," oppositional discourses of this kind, accentuate the language rights of speakers of a local tongue which has not been granted official recognition. Also 
embedded in this style of oppositional discourse is commonly a belief in linguistic purism: from the campaigner's perspective, languages have a life of their own and human intervention in natural development of the language should be condemned.

\subsection{Idea of language as a tool}

Another important cluster of oppositional discourses contests the idea of language as a tool. Such discourses are typically characterized by an emphasis on the instrumental functions of a language. They challenge judgements of pragmatic value associated with particular language policies or strategies. As has been suggested above, despite the fact that between 74 and $79 \%$ of the population of Singapore is ethnic Chinese (the figure slightly fluctuated between 1970 and 2010; Singapore Department of Statistics), former Prime Minister of Singapore Lee justified his decision not to adopt Chinese as country's lingua franca by citing extrinsic incentives: "Singapore would be economically isolated from the wider world if Chinese was chosen. And China then could not be of much help to our economic development” (Lee 2011). Similarly, Monsanto (2009) argues that Filipino cannot offer what English does for the Philippines, stating: "This country has survived well with English as its principal medium of instruction and communication. In fact, most of us concede it has given us an edge over other countries that spurn the English language."

In such contestatory discourse, the speaker or writer typically adopts the strategy of focusing on what a particular language does not do, rather than what it does do. This focus of discussion - not only that adopted by the speaker, but as a result the focus any interlocutor has to engage with - is shifted away from concern with language rights to problems not easily resolved by promoting use of a native tongue. The wider rhetorical strategy at work involves viewing any given language as a means to a specified end (economic competitiveness; effectiveness of the system of law; etc.), then assessing its usefulness purely on that basis.

\subsection{Pragmatic considerations merely hijack the discourse on multilingualism}

Contrastingly, there are commentators and campaigners who frame their discussion of the topic as complaint that pragmatic considerations merely hijack the 
discourse on multilingualism. For example David Spinnler, a Swiss journalist at Radio and Television Romansh, has warned that over-emphasis on pragmatic value risks a loss of heritage and culture: "Of course, in economic terms, you could get rid of all the languages and replace them with English... but if Romansh didn't exist, Switzerland wouldn't exist. Because Romansh is representative of the cultures and microcosms which make up Switzerland" (LeyboldJohnson 2006b).

Nationalists in South Korea argue that the ideology of a neo-liberal market economy should not justify the adoption of English as an official language, and that globalization is a homogenizing process (Yoo 2005). In Ireland, a further basis for this line of argument is concern about the vitality of the Irish language (Ó Gairbhí 2013).

\subsection{Inertia associated with changing language habits}

Another oppositional strategy uses selected images, examples and stories to highlight inertia associated with changing language habits (an argument especially prevalent in the legal context; see discussion in Tiersma 1999). When encountered in relation to legal multilingualism, such claimed inertia can result in a striking contrast between positive changes that policymakers envision and the commitment of practitioners who would appear well-positioned to bring about change. Attention tends to be given, in this way of thinking, to practical obstacles, such as lack of legal professionals proficient in the prescribed official language(s), or to costs involved in translation and in providing multilingual services. In some legal jurisdictions, it may be argued, a multilingual policy might become law but without sufficient measures be put in place (such as education, training and retraining of legal practitioners) to facilitate implementation of the policy; the result would be a lack of momentum in giving effect to the policy resulting in a form of linguistic re-colonization, paradoxically with the new multilingual legal system offering an entry point. Such a line of resistance arises mostly from practitioners in the legal and language professions themselves, who might otherwise be seen as, in this respect, local holders of power and change initiators. Such critiques appear prevalent in postcolonial legal jurisdictions, where legal professionals may in practice be reluctant to change the way they have been trained to practice; and since English is effectively the language of globalization, they may also be "loath to cut themselves off from international developments in their fields," with the result that attempts to legislate in favor of use of indigenous languages may fail (Schiffman 1996: 16). 
In some postcolonial jurisdictions, legal professionals confess directly that they do not have the linguistic repertoire to be able to provide legal services in the native language even if they are capable of speaking that language for other purposes. For example Lee, a Malaysian lawyer who was educated in both Singapore and the UK, writes that he does not "look forward" to his appearances in the lower courts where BM is used, because his command of Malay is "atrocious" (Lee 2008). He comments that it is "a pity" the Malaysian courts have adopted BM. Similarly, elite lawyers in Hong Kong, many of whom speak Cantonese fluently in their daily life, are unenthusiastic about using the local tongue in a legal context. An anonymous lawyer interviewed by Ng commented that, "I really don't pay much attention to the Chinese translation of a legal term. I use English most of the time. When I really, really have to use Chinese, I'll call up my friends in the last minute for help” ( $\mathrm{Ng}$ 2009: 212). Since both Malaysia and Hong Kong are common law jurisdictions, legal professionals recognize the importance of English as their conduit to legal cases and references elsewhere, and find it difficult to see how the local tongue will help them with their job. Being familiar with established discourses and values associated with language rights, however, legal professionals rarely disagree openly with the proposition that the local tongue should be used in a legal context. Yet many may demonstrate complacency, even unwillingness, to participate in actively pursuing this policy goal, offering as reasons the difficulties presented in bringing about change such as levels of language competence, efficiency and cost.

\subsection{Attack the linguistic properties of the language}

Finally, perhaps the most significant rhetorical strategy to be found both in relation to multilingualism in general and legal multilingualism in particular is that of seeking to attack the linguistic properties of the language in question. This form of argument is not new but is especially important in relation to law: when Law French was the dominant language in England between the twelfth and fifteenth centuries, English was seen as inferior to French because of its lack of precision (Tiersma 1999); in postcolonial jurisdictions today there is a tendency for legal professionals to argue that the native language is inadequate for legal argumentation (ironically, this includes former British colonies where English is held to be a better legal language than native languages because it is more precise). By such means, justification of a language preference ultimately based on social power is transformed into an apparently more 
specialised linguistic discourse concerned with inherent characteristics of the particular languages involved, with the implication that one language is inferior to another and hence unsuitable for its assigned purpose (in this case, for specialized legal use). ${ }^{14}$

A more extreme, or perhaps merely more explicit, example of opposition to legal multilingualism along these lines can be found among educated elites in the Philippines, some of whom appear to view Filipino as inferior to English because they associate it with illiterate people at the lower end of the social hierarchy. Publisher Teodoro Locsin Sr. writes in a newspaper article that, unlike English, which is "the language of knowledge for Filipinos," Tagalog is "the language of ignorance" and Filipino is "stupid and idiotic" (Locsin 1993, cited in Maceda 2003: 99). More moderate criticism does not deny inherent value of the national language; instead it suggests that the language is somehow linguistically not ready, at least as a legal language. This has been presented in the form, for example, that "the language of the law has not yet been fully developed or 'cultivated' in Filipino” (Gonzalez 1996: 231). This line of argument attempts to detach itself from notions of class, race or social power. It engages in an intellectual discussion about the nature of language and the need to expand the language's lexicon or develop an appropriate register to make possible its use in legal proceedings. In Japan, it has been argued that "the vague nature of the Japanese language allows obfuscation" and therefore it may be a good idea to adopt English as another official language (Tolbert 2003).

In the relatively new bilingual legal jurisdiction of Hong Kong, the local dialect Cantonese, which was introduced as a medium of legal proceedings less than two decades ago, has been similarly criticized as "not very respectful and proper," "undignified," and having "a very low level of precision” by legal professionals ( $\mathrm{Ng}$ 2009: 211, 215, 217). This is similar to what happened in Malaysia, where legal practitioners considered the Malay legal lexicon inadequate for modern legal arguments (Powell 2004), and similar to what happened in relation to Bahasa Malaysia (BM), which "does not have enough words to express legal concepts or complex arguments," "lacks the subtlety English has," and "lacks the directness that English language permits" because it is a new and euphemistic language. By contrast, English is claimed to be more "precise" and “efficient” as a legal language (Azzat 2001). Azzat (2001) illustrates this point with

14 In some arguments made on this point there is a strong element of linguistic determinism. Since most of the jurisdictions in question retain aspects of an imported legal system, the local tongue does not share a social history with the language in which the legal system was developed and typically operates, such as the legal language of Portuguese in East Timor (see Justice System Monitoring Programme 2011). 
a metaphor that describes BM as an unfit tool for law: "I often compare the use of $\mathrm{BM}$ in legal arguments to the use of a hammer instead of a screwdriver. The job will indeed be done but it will be messy and brutal whereas the use of English would be like using a screwdriver - elegant and each turn of the argument can be appreciated."

Metaphors such as that of the hammer and screwdriver used here, however, convey a fairly static view of language as a set of tools created for a predetermined, immalleable function; they also reduce perceived differences between BM and English to ones based on structure and vocabulary, rather than on patterns of use and resonances which cumulatively build prestige (and which cannot build prestige without use since, as long as the foreign import is held as the ideal, native languages will be obliged to wear borrowed garments that do not fit perfectly and will not be able to develop in relevant respects). Mazrui and Mazrui (1998) argue, in the African context, that marginalized languages are simply denied an opportunity to develop a legal register. Emphasising some of the wider discourse characteristics rather than vocabulary and grammar, by contrast, David (2003) has shown how Malaysian lawyers code-switch from BM to English in order to emphasize a point, confirming that use of the English language is itself an indicator of power.

\section{Conclusion}

My discussion above has explored three interwoven aspects of language status in multilingual jurisdictions: firstly, status labels they assign to languages, and their comparative significance; secondly, how their multilingual policies are promulgated, especially how elevation of the status of a language is justified; thirdly, rhetorical strategies used to oppose that kind of justification.

Perhaps unsurprisingly, and as my account above suggests, official portrayals of multilingual policies tend to prioritize general and popular values, including individual rights, equality, diversity, value and unity, alongside more directly functional benefits. Different weight is given to these various notions in promoting any given country's multilingual policy. Combining policy considerations comes at a cost. Diversity, for instance, needs to be balanced against unity; individual rights and equality cannot be applied without qualification, in relation to language as in other contexts; and functional benefits cannot simply override the other values, which are often viewed as fundamental. Moreover, since raising the status of any one language inevitably results in a hierarchy affecting other, surrounding languages, the same notions 
of diversity, individual rights, equality, etc. can be deployed to argue in favor of improved status for minority linguistic communities with inferior language status, rather than promoting the cause of some more fortunate, newly elevated or about-to-be-elevated language. Whether governments should lean towards diversity (Kukathus 2003) or equality (Kymlicka 2002) is still an ongoing political debate. The contention of this paper is that neither of these broad notions, on its own, can adequately justify the choice of one legal language over another.

The complexity, and potential inconsistency, of official arguments advanced in favor of a specific form of multilingualism - typically involving some combination of national, official, authentic, working and other languages - surface in opposing forms of argument aimed at undermining the outcome of the general language policy. That is why I have highlighted the various, often neglected rhetorical tropes and styles of argument at work in the development of such oppositional viewpoints, which are directed especially at preferential status accorded to one or more legally privileged languages. These arguments, it is suggested, may prove more illuminating than official statements in characterizing legal multilingualism in that they expose difficulties and contradictions about which official voices are often strategically silent.

The paper has also showed that when a language policy is formulated, discussion of linguistic communities as social groups (which are only partly defined by their use of a particular language, since they are likely also to share cultural, socio-economic and/or ethnic characteristics) is commonly inflected towards, and essentially disguised as, intellectual debate about the properties and capabilities of specific languages. This peculiar way of arguing over language policy is what makes rhetorical strategies in support of positions in language disputes especially interesting and important: their transformation of necessary debate about social groups, language use and power relations into a (not always well-informed) discussion about abstract properties of language involves an uncomfortable form of interdiscursivity, or appropriation of resources from one specialized genre into another (Bhatia 2010).

Such recasting of the basis of argument about language and language policy may be helpful to those who engage in it as a means of gaining legitimacy and apparent objectivity. By appealing to the technicality of legal language, for example, or the necessary solemnity of the courtroom, discussants are able to describe one language as being better adapted than another by being more "proper" or "precise," rather than engaging with historical or social issues. At the same time, this form of discourse may conceal a less palatable reality: that, in holding a particular language to be "stupid" or "idiotic" in itself, the commentator is projecting onto the system of language his or her feelings 
towards the linguistic community who use that language. As Blackledge (2005: 31) has put it, “(a)ttitudes to, and beliefs about, language, are often not only about language.”

Comparative analysis of rhetorical devices used in promoting and opposing officially adopted languages of the kind I have undertaken in this paper, it is suggested, is significant because it reveals points of tension between linguistic communities, gaps between policy and reality, mismatches between political and professional goals, leftover challenges involved in decolonization, folk understanding about language, and potential abuse of intellectual discourses in political debate. In addition, cross-jurisdiction comparison provides an important means of identifying those rhetorical devices which find their way into discourse on multilingualism, especially legal multilingualism, in many different places and which would otherwise remain invisible or be taken as merely isolated cases rather than a systemic feature of such situations.

Identifiable argumentative patterns may prove useful, in the longer term, in investigating multilingual policies as they are formulated and debated in various countries in the future. For example, with regard to Southeast Asia, the multilingualism discourses discussed in this article seem to lend support to Barr and Skrbis (2008)'s model of nationalisms, which organizes countries into a continuum on the basis of official attitudes shown towards ethnicity as an element of national identity. In Barr and Skrbis's model, to pursue the connection a little further, Malaysia tends towards an "ethnocultural" approach in nation building, while Singapore is closer to the "civic" end of the spectrum (2008: 4). Malaysia, for instance, insists on use of BM as the language of the court (unless the interest of justice demands otherwise), even though BM as a language represents cultural heritage, despite the popularity of English in inter-ethnic communications in the country. In Singapore, on the other hand, discourse on multilingualism is dominated by the theme of pragmatic values and the needs of Singapore as a modern country. Analysis of such features of postcolonial societies, and their deep interconnection with language, is especially important because continued negotiation of language status is both a prime site for ideological conflict, as well as conflict more directly focused on class and racial politics, as well as an important resource for movement towards future civil well-being.

Acknowledgement: The author would also like to thank Professor Alan Durant, Professor Malcolm Coulthard, Professor Christopher Hutton, and Dr. Frederick Blumberg for their constructive feedback on earlier drafts of this paper. Part of 
this paper has been presented in a Regional Conference of the International Association of Forensic Linguistics (Kuala Lumpur, 2012).

Funding: This research (code HKU 747812H) has been generously supported by the RGC General Research Fund.

\section{References}

Abdelhay, A. K., B. Makoni \& S. B. Makoni. 2011. The Naivasha language policy: The language of politics and the politics of language in the Sudan. Language Policy 10(1). 1-18.

Ahuja, A. 2011. Analysis: As Thais vote, a struggle with education. Reuters, 30 May. http://www.reuters.com/article/2011/05/30/us-thailand-education-idUSTRE74TONV20110 530 (accessed 2 December 2015).

Ammon, U. 2006. Language conflicts in the European Union: On finding a politically acceptable and practicable solution for EU institutions that satisfies diverging interests. International Journal of Applied Linguistics 16(3). 319-338.

Azzat, F. 2001. The language of the court. Malaysiakini.com, 3 July. http://www.malaysiakini. com/letters/8743 (accessed 2 December 2015).

Ball, D. 2011. Swiss effort to save a language opens a rift. Wall Street Journal, 1 September. http://online.wsj.com/article/SB10001424053111903352704576540252076676760.html (accessed 2 December 2015).

Barr, M. D. \& Z. Skrbis. 2008. Constructing Singapore: Elitism, ethnicity, and the nation-building project. Copenhagen: NIAS Press.

Bhatia, V. K. 2010. Interdiscursivity in professional communication. Discourse and Communication 21(1). 32-50.

Blackledge, A. 2005. Discourse and power in a multilingual world. Amsterdam \& Philadelphia: John Benjamins.

Burns, R. P. 2003. Rhetoric in the law. In Walter Jost \& Wendy Olmsted (eds.), A companion to rhetoric and rhetorical criticism, 442-456. Malden, MA: Blackwell.

Dacey, J. 2009. Make English an official language, study urges. Swissinfo, 18 February. http://www.swissinfo.ch/eng/Home/Archive/Make_English_an_official_language,_study urges.html?cid=7224750 (accessed 2 December 2015).

David, M. K. 2003. Role and functions of code-switching in Malaysian courtrooms. Multilingua 22(1). 5-20.

European Commission Directorate-General for Translation. 2010. Lawmaking in the EU multilingual environment. Luxembourg: Publications Office of the European Union.

Fettes, Mark. 1998 Life on the edge: Canada's aboriginal languages under official bilingualism. In Thomas Ricento \& Barbara Burnaby (eds.), Language and politics in the United States and Canada, 117-149. Mahwah, NJ: Lawrence Erlbaum.

Fishman, J. A. 1972. Language in sociocultural change. Stanford: Stanford University Press. Gateraruke, Raymond. 2012. Overview of Rwandan legislative process. Loophole 1. 35-41. Goldsmith, R. 2011. South Sudan adopts the language of Shakespeare. BBC, 8 October. http://www.bbc.co.uk/news/magazine-15216524 (accessed 2 December 2015). 
Goodrich, P. 1987. Legal discourse: Studies in linguistics, rhetoric, and legal analysis.

New York: St. Martin's Press.

Gonzalez, A. 1996. Incongruity between the language of the law and the language of court proceedings: The Philippine experience. Language and Communication 16(3). 229-234.

Grin, F. 1998. Language policy in multilingual Switzerland: Overview and recent developments (ECMI briefs 2). Flensburg: European Centre for Minority Issues.

Hashimoto, K. 2002. Implications of the recommendation that English become the second official language in Japan. In A. Kirkpatrick (ed.) English in Asia: Communication, identity, power, and education, 63-74. Melbourne: Language Australia.

Hornberger, N. H. 2001. Multilingual language policies and the continua of Biliteracy: An ecological approach. Language Policy 1. 27-51.

Justice Findlay. 1999. A view from the bench. Hong Kong Lawyer, August.

Justice System Monitoring Programme. 2011. Overview of the Justice Sector. Justice Facility:

A Bilateral Co-operation between the Governments of Timor-Leste and Australia 2008-2013.

Krzyżanowski, M. \& R. Wodak. 2011. Political strategies and language policies: the European Union Lisbon strategy and its implications for the EU's language and multilingualism policy. Language Policy 10. 115-136.

Kukathas, C. 2003. The liberal archipelago: A theory of diversity and freedom. Oxford: Oxford University Press.

Kukathas, C. 2002. Equality and diversity. Politics, Philosophy and Economics 1. 185-212.

Kymlicka, W. 2002. Contemporary political philosophy: An introduction. Oxford: Oxford University Press.

Lee, K.Y. 2011. Speech given at the Launch of the English Language Institute of Singapore (ELIS) on 6 September. http://www.moe.gov.sg/media/speeches/2011/09/06/speech-by-mr-leekuan-yew-at-elis-launch.php (accessed 2 December 2015).

Lee, S. 2008. The national language in the courts. http://shih.blogspot.hk/2008/04/nationallanguage-in-courts.html (accessed 2 December 2015).

Leung, J. 2012. Statutory interpretation in multilingual jurisdictions: Typology and trends. Journal of Multilingual and Multicultural Development 33(5). 481-495.

Leung, J. 2013. Cross-jurisdiction appropriation of the equal authenticity principle. Journal of Legal Pluralism 45(2). 209-226.

Leung, J. Forthcoming. Multilingual legal order. New York: Oxford University Press.

Leybold-Johnson, I. 2006a. Controversy rages over standardised Romansh. Swissinfo, 8 August. http://www.swissinfo.ch/eng/specials/romansh/Controversy_rages_over_standardised_ Romansh.html?cid=41074 (accessed 2 December 2015).

Leybold-Johnson, I. 2006b. Official Romansh still has some way to go. Swissinfo, 8 August. http://www.swissinfo.ch/eng/specials/romansh/Official_Romansh_still_has_some_way_ to_go.html?cid=41072 (accessed 2 December 2015).

Lim, L., A. Pakir \& L. Wee.2010. English in Singapore: Policies and prospects. In Lisa Lim, Anne Pakir \& Lionel Wee (eds.), English in Singapore: Modernity and management, 3-18. Hong Kong: Hong Kong University Press.

Lucini, D. 2004. Romansh row inspires strong language. Swissinfo, 6 October. http://www.swissinfo.ch/eng/Home/Archive/Romansh_row_inspires_strong_language. html?cid=4132548 (accessed 2 December 2015).

Macalister, J. 2012. Language policies, language planning, and linguistic landscapes in Timor-Leste. Language Problems and Language Planning 36(1). 25-45. 
Maceda, T.G. 2003. The Filipino national language: Discourse on power. In K. L. Adams et al. (eds.), Papers from the seventh annual meeting of the southeast Asian linguistics society, 99-108. Tempe: Arizona State University, Program for Southeast Asian Studies.

Mazrui, A. A. \& A. M. Mazrui. 1998. The power of Babel: Language and governance in the African experience. Chicago: Chicago University Press.

McRae, K. D. 1983. Conflict and compromise in multilingual societies: Switzerland. Waterloo: Wilfrid Laurier University Press.

Mesthrie, R. 2002. South Africa: A sociolinguistic overview. In R. Masthrie (ed.), Language in South Africa, 11-26. Cambridge: Cambridge University Press.

Monsanto, S. L. 2009. But Tagalog is Greek in Visayas, Mindanao. Philippine Daily Inquirer, 5 October. http://article.wn.com/view/2009/10/04/But_Tagalog_is_Greek_in_Visayas_ Mindanao/ (accessed 2 December 2015).

Morrison, K. \& I. Lui. 2000. Ideology, linguistic capital, and the medium of instruction in Hong Kong. Journal of Multilingual and Multicultural Development 21(6). 471-486.

$\mathrm{Ng}$, K. H. 2009. The common law in two voices. Stanford: Stanford University Press.

Ó Gairbhí, S. T. 2013. Let's not lose our native tongue in outer space. Irish Times, 21 February. http://www.irishtimes.com/debate/let-s-not-lose-our-native-tongue-in-outer-space-1. 1313679 (accessed 2 December 2015).

Office of the Commissioner of Official Languages. 2010. Official languages at the heart of our identity: An overview of the official languages act. Minister of Public Works and Government Services Canada.

Phillipson, R. 1992. Linguistic imperialism. Oxford: Oxford University Press.

Powell, R. 2004. Terminological creation and language shift in Malaysia's legal system. Current Issues in Language Planning 5(2). 109-130.

Rappa, A. L. \& L. Wee. 2006. Language policy and modernity in Southeast Asia. New York: Springer.

Riendeau, R. 2007. A brief history of Canada, 2nd edn. New York: Infobase.

Romaine, S. 2013. Politics and policies of promoting multilingualism in the European Union. Language Policy 12. 115-137.

Rubrico, J. G. 2001. The metamorphosis of Filipino as national language. Philippine Daily, 28 August. http://www.seasite.niu.edu/Tagalog/essays_on_philippine_languages.htm (accessed 2 December 2015).

Safran, W. 2004. Introduction: The political aspects of language. Nationalism and Ethnic Politics 10(1). 1-14.

Schiffman, H. F. 1996. Linguistic culture and language policy. London \& New York: Routledge.

Schmitt, N. 2005. Swiss confederation. In J. Kincaid \& G. A. Tarr (eds.), A global dialogue on federalism: Constitutional origins, structure, and change in federal countries, 347-380. Montreal \& Kingston: McGill-Queen's University Press.

Schmitt, N. n.d. Switzerland. Forum of federations and international association of centers for federal studies. http://www.thomasfleiner.ch/files/categories/IntensivkursIl/ Switzerlandg1.pdf (accessed 2 December 2015).

Shelton, D. 1997. Reconcilable differences: The interpretation of multilingual treaties. Hastings International and Comparative Law Review 20. 611-638.

Singapore Department of Statistics. 2010. Census of population 2010 advance census release. http://www.singstat.gov.sg/publications/publications-and-papers/population/census10_adr (accessed 2 December 2015). 
Song, J. J. 2011. English as an official language in South Korea: Global English or social malady? Language Problems \& Language Planning 35(1). 35-55.

Svartvik, J. \& G. N. Leech. 2006. English: One tongue, many voices. Houndmills: Palgrave Macmillan.

Tiersma, P. M. 1999. Legal language. Chicago \& London: University of Chicago Press.

Tolbert, K. 2003. English could become Japan's official second language. The Guardian, 23 February 2000. http://www.theguardian.com/education/2000/feb/23/tefl1 (accessed 2 December 2015).

T. P. 2011. The language holding Malays, Tamils, and Chinese together. Economist, 2 January. http://www.economist.com/blogs/johnson/2011/01/Singapore (accessed 2 December 2015).

UNESCO Ad Hoc Expert Group on Endangered Languages. 2003. Language vitality and endangerment. http://www.unesco.org/culture/ich/doc/src/00120-EN.pdf (accessed 2 December 2015).

Warhol, L. 2012. Creating official language policy from local practice: The example of the Native American Languages Act 1990/1992. Language Policy 11. 235-252.

Yoo, O. K. 2005. Discourses of English as an official language in a monolingual society: The case of South Korea. Second Language Studies 23(2). 1-44. 